\title{
Informatization evaluation of water conservancy project construction management based on AHP fuzzy comprehensive evaluation method
}

\author{
Lingqing Meng ${ }^{1 *}$ \\ ${ }^{1}$ School of Management, Tianjin University of Technology, 300384 Tianjin, China
}

\begin{abstract}
With the development of network technology, information evaluation gradually began to be used in all walks of life.As an important part of information construction,water conservancy informatization has developed rapidly. In order to accurately evaluate the degree of water conservancy informatization construction,the index system of water conservancy project construction management informatization is established by analytic hierarchy process, and the evaluation model of water conservancy project construction management informatization is obtained by combining fuzzy evaluation method. The evaluation model is used to comprehensively evaluate the degree of water conservancy informatization construction in a certain area,and it is found that the degree of water conservancy informatization in this area is good,and the evaluation results are consistent with the actual situation in this area. The evaluation grade of each evaluation index in the index system is determined,and some suggestions are put forward to promote the balanced and stable development of water conservancy informatization in this area,so as to provide reference for the evaluation of water conservancy informatization in other areas.
\end{abstract}

\section{Overview}

With the rapid development of network technology, information construction has become one of the inevitable topics in a country and an industry ${ }^{[1]}$. Since the Eleventh Five-Year Plan, China has gradually formed the development goal and guiding ideology of informatization construction, and proposed to build China into a big country with informatization and industrialization ${ }^{[2]}$. As an important part of China's informatization construction, water conservancy informatization has very typical and unique characteristics compared with other informatization industries, which is characterized by many departments, wide fields and strong professional nature ${ }^{[3]}$, which makes water conservancy informatization construction more difficult, and water conservancy project construction management informatization construction has encountered many difficulties ${ }^{[4]}$. Experts at home and abroad have done a lot of research on the informatization construction of water conservancy project construction management. Among them, the National Bureau of Statistics put forward six evaluation indicators of water conservancy informationization in line with China's actual situation; Bi Mingshan ${ }^{[5]}$ et al,established an information project evaluation model for hydropower enterprises; $\mathrm{Lu}$ $\mathrm{Xin}^{[6]}$, etc., combined with the evaluation index system at home and abroad, established the evaluation index system of water conservancy informatization in China.

At present, although the informatization project has made some achievements in the index system and evaluation model, especially in the enterprise informatization evaluation, there are few informatization studies specific to a certain industry, especially in the evaluation of water conservancy project construction management informatization ${ }^{[7-8]}$. The existing informatization evaluation is often too macro, which is not suitable for the multi-stage informatization evaluation of water conservancy construction management, and it is difficult to make a reliable evaluation of the informatization construction of water conservancy construction management at the present stage. Moreover, most of the informatization evaluation at the present stage tends to post-project evaluation, and it is impossible to comprehensively evaluate water conservancy construction management projects from pre-project to project operation.Therefore, it is very important to propose an evaluation system for informatization construction of water conservancy construction management. In this paper, the water conservancy project construction management is taken as the research object, and a multilevel evaluation index system suitable for China's water conservancy projects is established.The corresponding evaluation model is established by using AHP and fuzzy evaluation method, and the current water conservancy project construction management project is evaluated to provide guidance for the later development and operation of the project.

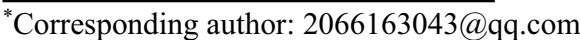




\section{2 index system}

\subsection{Principles of determining evaluation indexes}

The establishment of management index system of water conservancy project informatization construction is from the perspective of informatization evaluation, which provides guidance for the later development and operation of the project.The main means is to understand the informatization degree of water conservancy project construction management by analyzing the infrastructure and network system in the process of water conservancy project construction management at present, so as to provide guidance for future informatization construction. The determination of the evaluation index system follows the following principles:

Feasibility. The specific requirements are that the information index system is practical, simple and practical, and a reasonable system is constructed with fewer indicators.

Targeted. The index system should be put forward according to the informationization of water conservancy project construction management, and the index should highlight the project characteristics of water conservancy project construction management.

Integrity. Informatization evaluation is a systematic project, and the index system should fully reflect the systematic characteristics of water conservancy project construction management informatization, and the indexes should be independent of each other to avoid increasing workload.

Forward looking. The informatization evaluation of water conservancy project construction management has internet thinking, and its evaluation index should not only consider the current development achievements, but also consider the future development direction, which requires the index to be forward-looking to make the evaluation index system adapt to the development of the times.

\subsection{Evaluation index system}

According to the principle of determining evaluation indexes, combined with the national "Twelfth Five-Year Plan" evaluation on the achievements of water conservancy project construction management informatization stage, this paper sets out from three aspects: information technology level, business support degree and informatization guarantee, and constructs the first-level indexes of informatization evaluation, with three first-level indexes corresponding to multiple secondlevel indexes respectively,See Figure 1 for the evaluation index system of water conservancy project construction management informatization.

\section{Evaluation model}

\section{1 Determinate factor set comment set}

The factor set is the evaluation index, which is expressed as $U=\left\{u_{1}, u_{2}, u_{3} \ldots, u_{m}\right\}$, the evaluation index is shown in Figure 1 . Because the evaluation value of each evaluation index is inconsistent, different evaluation grades will be formed for each evaluation index, The comment set is the reflection of the evaluation grade corresponding to each evaluation factor (evaluation index), using the set $V=\left\{v_{1}, v_{2}, v_{3} \ldots, v_{n}\right\}$, this paper divides the comment set into four grades: excellent, good, medium and failed.

\subsection{Determine the weight of each index}

Because analytic hierarchy process is a commonly used system evaluation method, this paper uses analytic hierarchy process to determine the index weight. When determining the index weight by AHP, it is necessary to decom pose the target into several parts and make a layered structure, and then compare the relative importance of each index to obtain a judgment matrix, and then determine the weight of each index. According to the indicators corresponding to the informatization index system of water conservancy project construction management in Figure 1, several experts are invited to evaluate the indicators, and the weight calculation results of the first-level indicators are obtained, as shown in Table 1.

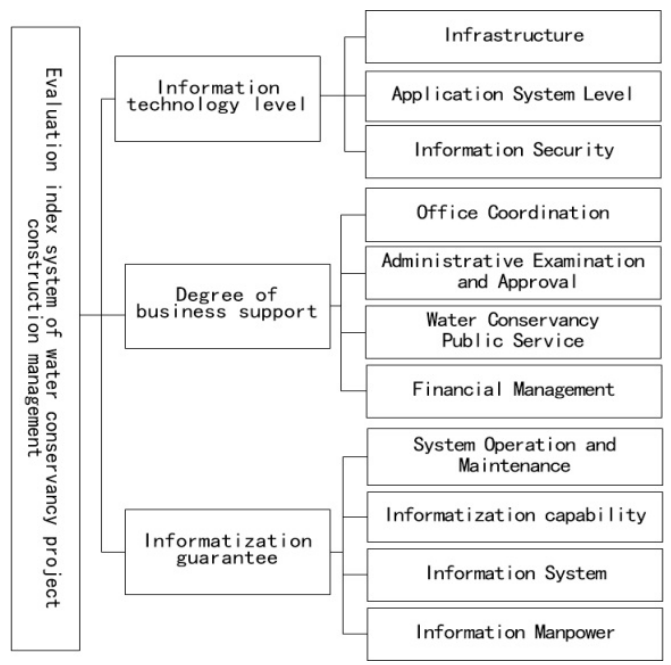

Fig.1 Evaluation index system of water conservancy

Table 1 First-class index weight

\begin{tabular}{|c|c|c|c|c|c|c|c|}
\hline Projects & $\begin{array}{c}\text { Degree of } \\
\text { business } \\
\text { support }\end{array}$ & $\begin{array}{c}\text { Information } \\
\text { technology } \\
\text { level }\end{array}$ & $\begin{array}{c}\text { Informatization } \\
\text { guarantee }\end{array}$ & $b_{i}$ & $w_{i}$ & $a \times w$ & \\
\hline Degree of business support & 1 & 1.13 & 1.41 & 1.17 & 0.39 & 1.16 & 1.00 \\
\hline
\end{tabular}




\begin{tabular}{|l|l|l|l|l|l|l|l|}
\hline Information technology level & 0.88 & 1 & 1 & 0.96 & 0.32 & 0.95 & 1.00 \\
\hline Informatization guarantee & 0.71 & 1 & 1 & 0.89 & 0.29 & 0.89 & 1.00 \\
\hline & & & & 3.02 & 1 & & 3.01 \\
\hline & & & & & CI & 0.003 & \\
\hline & & & & & CI/RI & 0.005 & \\
\hline
\end{tabular}

Table 2 Calculation results of index weights at all levels

\begin{tabular}{|c|c|c|}
\hline Target layer & Primary index & Secondary index \\
\hline \multirow{11}{*}{$\begin{array}{l}\text { Evaluation of } \\
\text { informatization } \\
\text { project level of } \\
\text { water } \\
\text { conservancy } \\
\text { project } \\
\text { construction } \\
\text { management } \\
\text { (B) }\end{array}$} & \multirow{3}{*}{$\begin{array}{l}\text { Information technology level } \\
\text { (B1) } 0.317\end{array}$} & Infrastructure (B11)0.418 \\
\hline & & Application System Level (B12)0. 255 \\
\hline & & Information Security (B13)0.327 \\
\hline & \multirow{4}{*}{$\begin{array}{l}\text { Business support level } \\
\text { (B2) } 0.388\end{array}$} & Office Coordination (B21)0.212 \\
\hline & & Administrative Examination and Approval (B22)0.237 \\
\hline & & Water Conservancy Public Service (B23)0. 224 \\
\hline & & Financial Management (B24)0. 327 \\
\hline & \multirow{4}{*}{$\begin{array}{l}\text { Information Guarantee } \\
\text { (B3)0.295 }\end{array}$} & System Operation and Maintenance (B31) 0. 205 \\
\hline & & Informatization capability (B32) 0.263 \\
\hline & & Information System (B33) 0.328 \\
\hline & & Information Manpower (B34) 0.204 \\
\hline
\end{tabular}

In Table 2, B represents the evaluation index of each level, and the weight set $A=\left\{a_{01}, a_{12}, a_{03}\right\}$ of the evaluation index respectively represents the first-level index weight vector, $A_{1}=\left\{a_{11}, a_{12}, a_{13}\right\}$ indicates the weight vector of each index $B_{11} 、 B_{12} 、 B_{13}$ under the first-level index $\mathrm{B} 1$, which is similar to $A_{2}$ and $A_{3}$.

\subsection{Construction of evaluation matrix and fuzzy subset}

The evaluation matrix $(\mathrm{R})$ is the fuzzy relation from the determined $\mathrm{u}$ to $\mathrm{v}$ of an evaluation object, that is, the fuzzy matrix is:

$$
R=\left(r_{i j}\right)_{m n}=\left[\begin{array}{ccc}
r_{11} & \cdots & r_{1 n} \\
\vdots & & \vdots \\
r_{m 1} & \cdots & r_{m n}
\end{array}\right]
$$

In which $r_{i j}$ is the frequency distribution of the ith index $u_{i}$ on the jth comment ${ }^{v_{j}}$, and $r_{i j}$ satisfies that the sum of all frequencies is 1 .

Because the weight value of each index is inconsistent, that is, the proportion of each index in the overall evaluation index system is inconsistent, the fuzzy relation matrix calculated from this can not effectively evaluate the evaluation object, so the concept of fuzzy subset needs to be introduced when using fuzzy matrix to evaluate, where fuzzy subset:

$$
M=\left\{m_{1}, m_{2} \cdots m_{n}\right\}
$$

In which $M=A \times R, m_{n}$ represents the degree of vn of the evaluated object, and the sum of all fuzzy evaluation degrees is 1 ; If it is not 1 , it should be normalized.

\section{Application examples}

The informatization construction of water conservancy construction management is being carried out in a certain place, and the informatization degree of water conservancy construction management in this place is evaluated by using the index system and corresponding evaluation model proposed in this paper. In this evaluation, employees, experts in information technology, teachers in relevant scientific research institutions and the public are required to conduct comprehensive scoring evaluation, and then the average score of the above four aspects is taken as the final result. To ensure the scientific and reliable evaluation results, the corresponding fuzzy matrix is calculated as follows:

$$
\begin{aligned}
R_{1} & =\left[\begin{array}{llll}
0.41 & 0.36 & 0.22 & 0 \\
0.27 & 0.38 & 0.32 & 0.03 \\
0.3 & 0.41 & 0.23 & 0.06
\end{array}\right] \\
R_{2} & =\left[\begin{array}{cccc}
0.68 & 0.2 & 0.12 & 0 \\
0.23 & 0.52 & 0.25 & 0 \\
0.23 & 0.32 & 0.25 & 0.2 \\
0.3 & 0.35 & 0.25 & 0.1
\end{array}\right] \\
R_{3} & =\left[\begin{array}{cccc}
0.21 & 0.47 & 0.12 & 0.2 \\
0.3 & 0.55 & 0.15 & 0 \\
0.23 & 0.37 & 0.3 & 0.1 \\
0.3 & 0.38 & 0.32 & 0
\end{array}\right]
\end{aligned}
$$

According to the calculation results of index weights at all levels, the comprehensive evaluation results are obtained

$$
\begin{aligned}
& M_{1}=\mathrm{A}_{1} \times R_{1}=\left(\begin{array}{llll}
0.338, & 0.382, & 0.253, & 0.027
\end{array}\right) \\
& M_{2}=\mathrm{A}_{2} \times R_{2}=\left(\begin{array}{lllll}
0.350, & 0.345, & 0.227, & 0.078
\end{array}\right) \\
& M_{3}=\mathrm{A}_{3} \times R_{3}=\left(\begin{array}{llll}
0.259, & 0.440, & 0.228, & 0.073
\end{array}\right)
\end{aligned}
$$

Establish the corresponding upper evaluation matrix 
by using the above evaluation indexes, and obtain the evaluation results of the target layer:

$$
M=\mathrm{A}_{0} \times R=(0.319, \quad 0.385, \quad 0.236, \quad 0.060)
$$

Using the above evaluation results, the evaluation index system and I are obtained. See fig. 2 and fig. 3 for the evaluation grade diagram of grade evaluation index evaluation.

It can be seen from Figure 2 that the comprehensive evaluation result of informatization level of water conservancy project construction management in this area is good, and the evaluation result is consistent with the actual construction level in this area. It can be seen from the comprehensive evaluation results of the first-level indicators in Figure 3 that the rating results of information technology level in this region are good, the degree of business support is excellent, and the degree of information security is good. Therefore, it is necessary to strengthen the development of information technology level and informatization guarantee degree in the process of informatization construction of water conservancy project management in this region, so as to ensure the balanced and stable development of each index in the process of informatization construction.

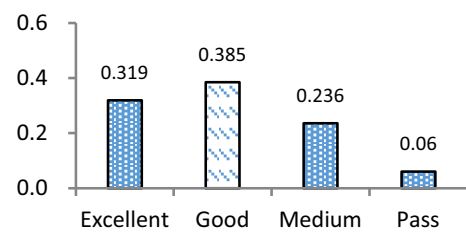

Fig.2 Fuzzy evaluation results of target layer

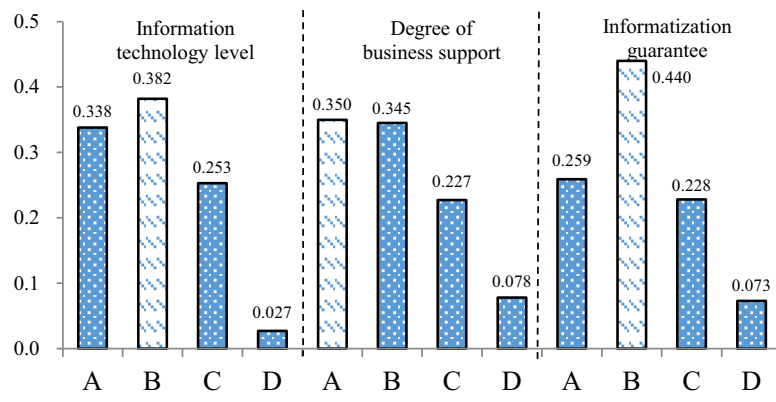

Note:In the table A, B, C, D respectively represent excellent, good, medium and pass

Fig.3 Evaluation results of primary indicators

\section{5 conclusion theory}

With the development of network technology, the importance of informatization construction has gradually become prominent.As an intuitive evaluation of water conservancy informatization construction, it is very important to accurately evaluate the informatization degree of water conservancy construction management. In this paper, the evaluation index system of water conservancy project construction management informationization is established by AHP, and the comprehensive evaluation model is determined by fuzzy evaluation method. The model is used to evaluate the informatization degree of water conservancy project construction management in a certain area of China, and the evaluation level of each evaluation index is
obtained.Suggestions are put forward to promote the balanced and stable development of water conservancy informatization in this area, and the rationality of evaluation index system and evaluation model is verified.The research results can provide reference for water conservancy informatization evaluation in other areas.

\section{References}

1. National Statistical Information Center. Measurement and comparative study of informatization level in different regions of China [j]. Statistical Research, 2001 (2): 3-11.

2. Editorial department .Seminar on the 13th Five-Year Plan of Water Conservancy Informatization Held . Water Conservancy Informatization, June 2014: 50-50 .

3. Pan Jie. Analysis of information construction of water conservancy design $[\mathrm{J}]$. Heilongjiang science and technology letter Interest, 2014(35): 20 .

4. Huang Xiaodong .Necessity and development trend of informatization construction of water conservancy projects.Henan Water Conservancy and South-toNorth Water Transfer, 2017,46 (12): 85-86 .

5. Bi Mingshan. Research on Evaluation Model of Electric Power Enterprise Informatization [D]. Tianjin: Tianjin University, 2008 .

6. Lu Xin and Zhao Fang. Fuzzy comprehensive evaluation method of enterprise informatization based on multi-level combination weight [j]. Journal of Hebei University (Natural Science Edition),2012,32( 3): $320-325$.

7. Shu Xiaopeng. Talking about how to use information technology to do well the safety management of water conservancy and hydropower projects $[\mathrm{J}]$. Jiangxi Chemical Industry, June 2017: 236-237 .

8. Ai Ping, Yuan Dingbo, Bian Shizhe, et al. Brief analysis method of water conservancy informatization development [J]. Water Conservancy Informatization, 2016 (6): 6-9 . 